\section{A Importância do Ensino à Distância na Educạ̧ão das Mulheres: Mundo Acadêmico e Inserção no Mercado De Trabalho}

\section{Resumo}

O objetivo principal deste artigo é entender a importância do ensino a distância para educação feminina e a inserção da mulher no mercado de trabalho, desde o ensino por correspondência até o EaD online, utilizando como fonte primária anúncios de revistas femininas a partir da década de 1950, de cursos enviados via correios aliados à conceituação e análise histórica de EaD, gênero e educação feminina no Brasil.

Palavras-chave: EaD. Mercado de Trabalho. Educação feminina. Gênero.

\section{Abstract}

The main purpose of this article is understanding the importance of distance learning to women education and their access to the labor market, since the correspondence learning until the distance learning. Using as first source, magazines advertisements from the 50's and correspondence courses, combining the concepts and historic analysis, distance learning, gender and women education in Brazil.

Keywords: Distance learning. Labor market. Women education. Gender.

\section{Introdução}

A ascensão de mulheres no mundo acadêmico e no mercado de trabalho é notória em todo o mundo, no entanto, os papéis desempenhados ainda são inferiorizados em relação aos homens. Atualmente, espera-se que a mulher moderna concilie os afazeres domésticos, manutenção do casamento e cuidados dos filhos com o
Prof. ${ }^{a}$ Dr. ${ }^{a}$ Ana Paula Galvão Damasceno Carrare

Ana Paula Galvão

Damasceno Carrare

Doutora em Ciências da

Saúde pela Faculdade

de Ciências Médicas da

Santa Casa de São Paulo

(2014). Bacharel em Ciência

da Computação pela

Universidade Cruzeiro

do Sul (2000), Mestre em

informática em Saúde pela

Universidade Federal de São

Paulo (2005) e Atualmente é

Professora Assistente I da

Universidade Cruzeiro do

Sul, Professora instrutora

da Faculdade de Ciências

Médicas da Santa Casa

de São Paulo e Revisora de periódico da Revista IEEE

América Latina.

\section{Prof. ${ }^{a}$ Nathalie}

Cristina Gularte

Rosa

Nathalie Cristina Gularte Rosa. Bacharel em História pela Universidade Cruzeiro do Sul (2015), Pós-Graduanda em Educação a Distância: Elaboração de materiais e tutoria em ambientes virtuais. 
trabalho remunerado. Entretanto, o mercado está cada vez mais exigente e demanda profissionais capacitados.

Nesse cenário, a Educação a Distância (EaD) se configura como uma alternativa ao ensino presencial, que demanda deslocamento espacial, tempo e mais dinheiro. A modalidade a distância, por suas características, que serão verificadas na pesquisa, tornou-se uma opção para grupos que buscam melhores condições no mercado de trabalho, por isso, as mulheres têm cada vez mais procurado essa opção ao invés do meio de ensino tradicional.

O ensino a distância no Brasil é uma modalidade antiga, que tem recebido o devido respeito há pouco tempo. No passado, o EaD era depreciado e visto com desconfiança, sobretudo no nível de educação superior. Por conta das inovações tecnológicas e características inclusivas, esse modelo educacional tem se destacado, reduzindo preconceitos e trazendo novos adeptos.

Com o intuito de contextualizar o presente trabalho será apresentado na próxima seção um estudo sobre a história da educação a distância e como ela se desenvolveu no Brasil. Em seguida, discorre-se sobre a educação feminina e a luta por direitos sociais e como o cenário da educacão a distância colaborou para a ascensão da mulher. Na sequência será analisado o percurso histórico dos cursos por correspondência e como eles chegaram às universidades. Por fim, será apresentada as considerações finais.

\section{Metodologia}

Para o desenvolvimento deste artigo, como fonte primária de pesquisa, foram utilizados 35 anúncios de revistas femininas de cursos por correspondência das décadas de 1950 a 1960, período nostalgicamente chamado em História como Os Anos Dourados.' Também foram

1 Período compreendido entre 1945 a 1964, marcados por grandes avanços científicos, tecnológicos, mudanças culturais e comportamentais. PINSK, Carla Bassanezi. Mulheres dos Anos Dourados. p.1-6 São Paulo: Contexto, 2014. utilizados dados disponibilizados no site do Ministério da Educação (MEC) e pela Associação Brasileira de Educação a Distância (ABED).

\section{EaD: História e Educação para a Diversidade}

A EaD é uma importante modalidade educacional, mediada pelas Tecnologias da Informação e Comunicação (TIC), que ajuda a democratizar o ensino, pois tem a capacidade de alcançar um grande número de pessoas nas mais variadas distâncias espaciais, proporcionando formação acadêmica de qualidade até mesmo para aqueles que não dispõem de tanto tempo e/ou dinheiro, pois geralmente os cursos ofertados têm valor inferior aos cursos da modalidade presencial.

\begin{abstract}
A Educação a Distância é a modalidade educacional na qual a mediação didático-pedagógica nos processos de ensino e aprendizagem ocorre com a utilização de meios e tecnologias de informação e comunicação, com estudantes e professores desenvolvendo atividades educativas em lugares ou tempos diversos. (MEC, 2019, online)
\end{abstract}

Essa definição está presente no Decreto 5.622, de 19.12.2005 - que revoga o Decreto $2.494 / 98$-, que regulamenta o Art. 80 da Lei 9.394/96 (LDB).

Hoje a EaD é uma importante modalidade educacional, mediada pelas TIC, que ajuda a democratizar o ensino, pois tem a capacidade de alcançar um grande número de pessoas nas mais variadas distâncias espaciais, proporcionando formação acadêmica de qualidade até mesmo para aqueles que não dispõem de tanto tempo e/ou dinheiro, pois geralmente os cursos ofertados têm valor inferior aos cursos da modalidade presencial.

Assim como a modalidade presencial, a EaD também proporciona um processo de ensino e aprendizagem onde discentes e docentes interagem com a troca de conhecimentos, relatos 
de experiências e vivências, por conta das tecnologias que possibilitam a transmissão de aulas via internet e/ou satélite. Devido a essas características, o modelo tem atraído cada vez mais público e se tornou uma importante ferramenta para a educação da diversidade, onde as mulheres atualmente são a maioria, de acordo com o Censo EaD 2017/2018 organizado pela Associação Brasileira de Educação a Distância (ABED), mas antes de abordar o objetivo central deste artigo, faz-se necessário discorrer sobre a história desse tipo de ensino no mundo e no Brasil.

A história da educação à distância internacional é marcada por três grandes gerações: a primeira tem como características cursos por correspondência, a segunda mídias e universidades abertas e a terceira define-se pelo ambiente online. A seguir, serão apresentadas algumas considerações sobre cada uma dessas gerações.

A primeira surge efetivamente em meados do século XIX, em virtude da segunda Revolução Industrial que desenvolve novos meios de transporte e comunicação, como os trens, carros, aviões, telefones, rádios etc. É caracterizada pela elaboração de materiais impressos e enviados aos alunos pelos correios. De acordo com João Mattar (2011), foram várias as iniciativas de criação de cursos à distância, a partir das quais surgiram sociedades, institutos e escolas voltadas para a modalidade. No entanto, os casos bem-sucedidos foram os cursos técnicos de extensão universitária, pois havia muita resistência a cursos universitários a distância, culminando em poucas experiências duradouras.

A segunda, caracteriza-se pelas universidades abertas e novas mídias, como a televisão, rádio, fitas de áudio e vídeo e telefone. De acordo com Mattar (2011, p.5) "um momento importante nessa segunda geração é a criação das universidades abertas de educação à distância, influenciadas pelo modelo de Open University, fundada em 1969". Essas universidades abertas realizaram experiências pedagógicas que utilizavam intensamente as novas mídias da época. Consequentemente, o interesse pela modalidade EaD, proporcionou o surgimento das megauniversidades em diversos países. Contudo, a rejeição ao EaD persistiu e apenas na década de 1990 as universidades tradicionais e as empresas passaram a se interessar pelas experiências inovadoras da EaD.

A EaD online é definida pelo início da utilização do videotexto, do microcomputador, do hipertexto, da tecnologia de multimídia e de redes de computadores. Atualmente essas multimídias se integram ao computador e diversas mídias das duas fases anteriores convivem, apesar da predominância da internet.

\begin{abstract}
Com o crescimento explosivo da Internet, pode-se observar um ponto de ruptura na história da EaD. Surge um novo território para a educação, o espaço virtual da aprendizagem, digital e com base na rede. Aparecem também várias associacões de instituições de ensino à distância. Passa-se simultaneamente a conceber um novo formato para o processo de ensino-aprendizagem, aberto, centrado no aluno, interativo, participativo e flexível. (MATTAR, 2011, p. 6)
\end{abstract}

Com a ruptura causada pela Internet, a EaD passou a atingir, utilizando sistemas mais ou menos sofisticados, milhões de pessoas em dezenas de países em todos os níveis de ensino. Assim como a Cruzeiro do Sul, que oferece cursos à distância completos nos níveis técnicos, da graduação e pós-graduação, são inúmeras as instituições ofertando cursos à distância. Atualmente, a EaD e o modo presencial convivem em harmonia nas universidades tradicionais, com ações inovadoras como os cursos híbridos, que têm configurado mais um novo avanço na modalidade, que no futuro poderá configurar um novo campo ainda mais revolucionário. Todavia, também existem universidades totalmente virtuais, que não possuem campus, chamada por Mattar (2011) de "Click Universities". Hoje as universidades abertas de todos os continentes ofertam cursos à distância, algumas até gratuitamente. Com a valorização da EaD, até mesmo empresas corporativas passaram a empreendê-lo. 
No Brasil, a EaD, inicialmente, seguiu o movimento internacional com a oferta de cursos por correspondência e acompanhou a evolução das novas tecnologias. De acordo com Mattar (2011, p. 57) "[...] as mídias como o rádio e televisão serão exploradas intensamente e com muito sucesso em nosso país, por meio de soluções específicas e muitas vezes criativas, antes da introdução da internet". Também é necessário esclarecer que é recente a experiência brasileira das universidades abertas com a criação da Universidade Aberta do Brasil. Na Figura 1 é possível verificar a síntese de alguns momentos históricos importantes para a EaD no Brasil.

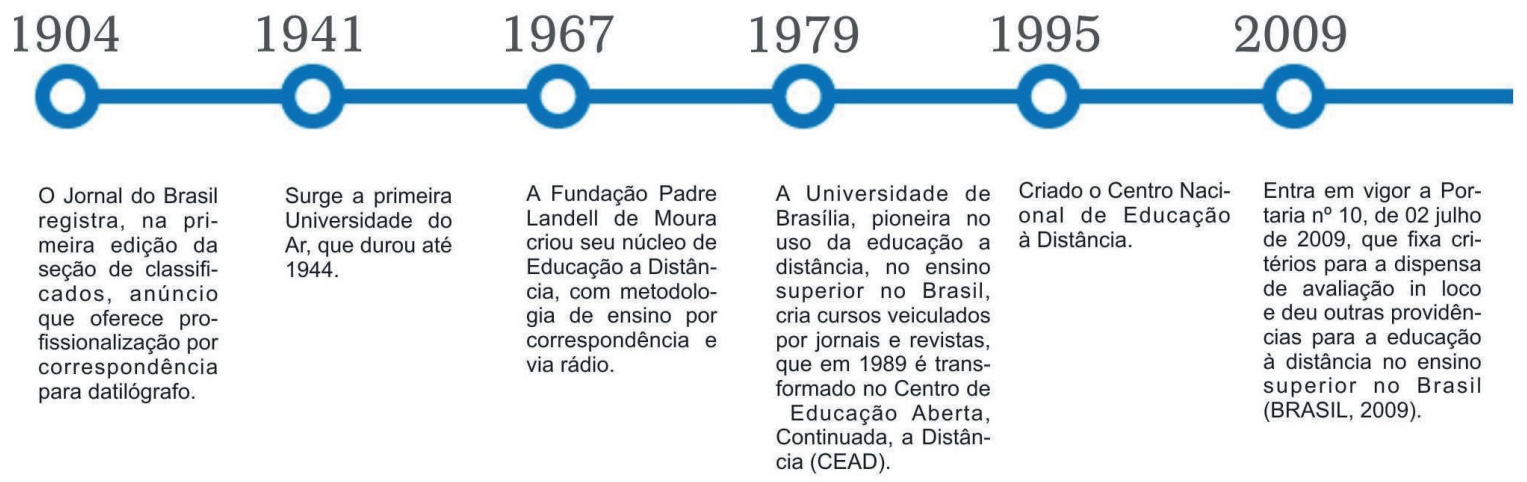

Figura 1 - Evolução histórica da educação à distância no Brasil.

Fonte: EaD UFPA

Em 1904, o Jornal do Brasil já registrava os primeiros anúncios de cursos EaD, que ofereciam profissionalização de datilografia por correspondência. Também é o ano do marco histórico da modalidade no país, pois houve a implantação das Escolas Internacionais, representando organizações norte-americanas. De acordo com Mattar (2011, p.57), apesar do período de crise educacional, o ensino por correspondência recebeu pouca atenção e incentivo dos órgãos governamentais.

Em 1923, iniciou-se a educação pelo rádio, com a fundação da Rádio Educativa, que ofertava cursos de português, francês, radiotelegrafia, telefonia etc. Nos anos seguintes várias rádios educativas foram fundadas e propunham o uso de recursos de rádio, cinema e impressos. $O$ contato com os alunos também era realizado via correspondência.

Nos anos 1939 e 1941 foram criados os dois primeiros importantes institutos de ensino à distância do país, o Instituto Monitor e o Instituto Universal Brasileiro, que tiveram milhões de alunos. São considerados os institutos pioneiros na oferta sistemática de cursos profissionalizantes por correspondência. Também ofertavam cursos elementares e técnicos, tendo como materiais apostilas impressas enviadas pelos correios.

De 1976 a 1992 foi criado Sistema Nacional de Teleducação e a Universidade Aberta do Brasil, momentos nos quais proporcionaram o surgimento, por exemplo, do Telecurso 2000 e de programas voltados à formação continuada de professores, como o Salto Para o Futuro.

Segundo Araújo, Silveira e Cechinel:

Os desdobramentos gerados pela nova Lei de Diretrizes e Bases da Educação [...] fizeram surgir, em 1996 a Secretaria Especial de Educação a Distância (Seed), com o objetivo de promover, regular e supervisionar a EAD no Brasil. (ARAÚJO; SILVEIRA; CECHINEL, 2016, p. 42) 
A partir de 2004 a 2009 a Educação a Distância começou a ser regulamentada no Brasil com portarias e decretos. Em 2011 a Seed foi extinta e segundo Araújo e colaboradores (2016) substituída pela Secretaria de Regulação do Ensino Superior (Seres), sistema regulado, mas que tinha lacunas relacionadas à EaD, aos polos, aos docentes e aos tutores. Consequentemente, em 2016 o Conselho Nacional de Educação propôs um novo marco regulatório, a Resolução CNE/CES n. ${ }^{\circ}$. A Educação à Distância, apesar de várias tentativas de sucesso remotas, estabeleceu-se no Brasil em 2000 com seus primeiros cursos, que eram oferecidos por instituições de ensino superior e universidades privadas. Hoje é vista por especialistas como a Tecnologia da Esperança, mas por quê?

O Brasil é um país de dimensão continental, com uma grande quantidade de analfabetos, localizados principalmente nos estados mais pobres. Além disso, o processo de industrialização foi intensificado nos últimos anos, mas ainda não existe mão de obra especializada suficiente para atender a demanda. De acordo com a Pesquisa Nacional por Amostra de Domicílio (Pnad), divulgada pelo Instituto Brasileiro de Geografia e Estatística (IBGE), o Brasil conta com 11,8 milhões de analfabetos, ou seja, homens e mulheres que não sabem ler e escrever. Nesse cenário de analfabetismo, a EaD desponta, de acordo com Martina (2018), como a Tecnologia da Esperança, pois a modalidade tem potencialidades de agregar os grupos ditos "excluídos", características que a educação tradicional não é capaz de desempenhar sozinha.

As potencialidades da EaD de combater o analfabetismo estão diretamente relacionadas às suas características de flexibilidade e interação, por isso é uma importante modalidade para a democratização do ensino. Além de colaborar para especialização da mão de obra, também auxilia na conscientização e debate político e social dos discentes no quais a maioria são mulheres, que durante anos lutam por melhores condições de trabalho e igualdade de direitos.

\section{Educação feminina e lutas por direitos sociais}

Os séculos anteriores ao XIX foram marcados pela ideologia de que a educação formal para mulher não era essencial. As únicas instruções necessárias eram as que preparavam as mulheres para o exercício de seus papéis femininos de mães, donas de casas e esposas. O mundo privado era o local de sociabilidade feminino, enquanto homens sempre tiveram livre acesso ao mundo das letras, mundo do trabalho e espaço coletivo. Nesse cenário, as diferenças sociais entre homens e mulheres eram reforçadas a partir da diferenciação educacional.

O século XIX foi o período no qual iniciaram-se os primeiros movimentos femininos em prol da conquista de direitos políticos e sociais das mulheres. De acordo com Bassanezi e Pedro (2014), ao lado da educação doméstica crescia a importância de educar formalmente meninas e moças a ler, escrever e entender as operações aritméticas básicas a fim de que, no futuro, se tornassem mães melhores que educariam os novos cidadãos das pátrias, que seriam os trabalhadores do futuro. Na intenção de criar mães melhores, começaram a surgir por todo o ocidente escolas, internatos e cursos privados do nível primário para ensinar mulheres o básico instrucional.

Inicialmente, o ensino misto não era permitido, por isso, as salas de aulas femininas eram compostas apenas por moças, acompanhadas por professoras mulheres. O ensino público, obrigatório e gratuito só era concedido a homens (BASSANEZI; PEDRO, 2014). Esse direito básico demorou vários anos para ser conquistado pelas mulheres.

\footnotetext{
Apesar dos obstáculos, a alfabetização de mulheres progrediu nas cidades do século XIX. Por volta de 1880, os principais países da Europa haviam implantado ou estavam em vias de implantar, um ensino primário (em escolas gratuitas) e secundários acessiveis a elas. A expansão da educação afetou significativamente a vida das mulheres que passaram a ter acesso ao domínio público da cultura e ampliar seus horizontes. (BASSANEZI; PEDRO, 2014, p. 275)
} 
Nesse cenário de ampliação da educação feminina, algumas mulheres começaram a produzir saberes e algumas iniciaram o exercício de funções como professoras, com direito a remuneração. Foi o início da entrada da mulher no mercado de trabalho. No entanto, é importante destacar que aqui se fala sobre a mulher europeia e norte americana de classe média e alta, pois mulheres pobres sempre participaram do mundo do trabalho, em funções muito inferiores à de homens e com salários miseráveis.

A mulher no magistério, inicialmente, causou polêmica entre professores, porque consideravam que a educação básica poderia ser drasticamente prejudicada pela presença feminina, pois a mulher era considerada intelectualmente inferior por alguns. Em contrapartida, os defensores das mulheres no magistério diziam que o exercício da profissão de professoras era uma extensão dos instintos maternos e qualidades femininas próprias e inerentes das mulheres. Com o passar dos anos, o magistério se tornou uma profissão de maioria feminina, no entanto, os salários eram inferiores ao de professores.

A entrada da mulher no ensino superior foi resultado de lutas travadas por aquelas que desejavam mais instrução e melhores postos e condições de trabalhos. Segundo Bassanezi e Pedro (2014), através de campanhas e manifestos, mulheres das classes alta e média reivindicavam os mesmos direitos de homens que frequentavam universidades. Uma das frentes de luta foi o acesso à educação igualitária para homens e mulheres, pois enquanto meninos avançavam no aprendizado de ciências, as mulheres aprendiam instruções básicas e as artes femininas obrigatórias como costura e bordado, ou seja, as mulheres não tinham a educação necessária para ingressar no mundo acadêmico.

De acordo com Bassanezi e Pedro (2014, p. 275), a lém de lutar contra o estado pelo direito à educação, as mulheres também precisaram lutar contra a mentalidade da época, pois as famílias, instituições de ensino, estudantes homens e legisladores se opunham a mulher na academia e fora do mundo privado. Com o passar dos anos, através dos embates, foram gradativamente conquistando direitos de entrar nas universidades, mas tiveram que enfrentar as desigualdades exercidas dentro das academias e quando finalizavam os cursos, precisavam batalhar para exercerem a profissão.

Aos poucos, as mulheres começaram a se formar em profissões consideradas masculinas como direito e medicina. Tais mulheres ampliaram as possibilidades femininas e foram importantes para as lutas feministas. É necessário evidenciar que os avanços femininos na educação e na conquista de direitos civis está intimamente ligado ao movimento feminista. A partir do século XX, principalmente por conta do período de guerras, o trabalho feminino ganhou destaque, sobretudo, no setor terciário. As mulheres eram convocadas a suprir a mão de obra masculina em níveis hierárquicos diversos, a fim de auxiliar no esforço de guerra. Gradativamente, foram ganhando espaço no mercado de trabalho e passaram a contribuir para a complementação da renda familiar. Assim, os argumentos contrários ao acesso feminino nos espaços de educação e mundo do trabalho foram sendo abrandados (BASSANEZI; PEDRO, 2014, p. 276).

No Brasil, assim como no exterior, a educação feminina e as conquistas dos direitos políticos e sociais das mulheres foram alcançadas pouco a pouco e enfrentaram grande resistência (BASSANEZI; PEDRO, 2014). A mentalidade da mulher ideal devotada ao lar, ao marido e aos filhos também era predominante no país e o espaço público era território masculino, assim como a educação, que era um privilégio exclusivo de homens.

Durante o período colonial, a educação era uma função executada pela Igreja Católica, sobretudo, pelos Jesuítas, que tinham como função a catequização de indígenas e a educação dos meninos, filhos dos colonos (ACORDI, 2001). Houveram algumas tentativas de "educar" índias, assim como os índios eram educados, mas a Coroa considerou tal prática imoral. Às mulheres de elite da colônia eram reservados o lar e as obrigações de manutenção da família. 
De acordo com Acordi (2001, p. 834), o interesse em atividades intelectuais para mulheres começa com o nascimento da modernidade no país, ou seja, no período Imperial, no qual existia um esforço maior pela modernização.

Com o fim da escravidão em 1888, a família burguesa requeria uma educação feminina tutelada pela mãe branca e retirada do seio da mulher negra ex-escrava - considerada ainda mais inferior que a mulher branca -. No entanto, de acordo com Fúlvia Rosemberg (2012, p. 334) a quantidade de mulheres analfabetas entre 1872 até 1950 permanecia quase a mesma e em números muito superiores e desiguais em relação aos homens.

Em 1827 foi autorizado o acesso de mulheres a escolas de primeiras letras, mas o acesso total e irrestrito só foi regulamentado em $1971 \mathrm{com}$ a Lei de Diretrizes e Bases. Tal qual os modelos internacionais, aqui salas mistas também não eram vistas com bons olhos, e a educação de meninas e moças deveria ser desempenhada também por mulheres. Havia a ideia de que mulheres eram menos capazes e inteligentes que homens, e que não necessitavam de ensino secundário, pois para o papel de "mães" apenas o ensino básico - leitura, escrita, e as quatro operações aritméticas - era necessário para o exercício da função de "rainha do lar".

De 1830 a 1840, as escolas normais, antes apenas masculinas, passaram a acolher mulheres para que se formassem professoras, com o intuito de formar moças nos ensinos básicos. As classes mistas começaram a se formar a partir dos anos de 1850, mas por motivos econômicos, pois a moral positivista e católica da época reprovava fortemente o convívio entre os gêneros masculino e feminino.

Assim como as mulheres europeias, a partir da década de 1950, no pós-guerra, as mulheres começaram a ganhar espaço no setor terciário, mas com salários inferiores aos dos homens e somente porque tiveram acesso à educação básica e algumas possibilidades de entrada no ensino secundário. Também foi um período no qual houve um crescimento de cursos profissionalizantes. Algumas conseguiram ser admitidas em universidades, mas o período de ascensão ao ensino superior em escala mais ampla se iniciou a partir da década de 70, com explosão do movimento feminista no Brasil.

Pode-se constatar que o movimento feminista foi muito importante para a ampliação da educação feminina e conquista de direitos políticos e sociais, por isso é importante destacar os principais momentos da história feminista que trouxeram o progresso para mulheres em todo o mundo. De acordo com Luciane Luz (2012), são três grandes ondas iniciadas em períodos distintos.

A primeira onda, iniciada na Europa, entre os séculos XIX e XX, com as sufragistas ${ }^{2}$, foi marcado pelo embate por direitos civis básicos, como o direito ao voto, emancipação feminina e acesso à educação. Nesse período, as feministas também já lutavam contra a mentalidade de que a mulher era inferior e incapaz, a fim de desnaturalizar as desigualdades entre homens e mulheres.

A segunda onda deu-se com a expansão do capitalismo nos EUA, no século XX. As reivindicações eram de cunho trabalhista e as feministas demandavam das empresas melhores condições de trabalho e aumento de salários.

\begin{abstract}
Algumas feministas denunciaram que as desigualdades entre homens e mulheres na esfera privada eram reproduções de valores machistas presentes na sociedade estadunidense da época. As americanas, que há muito questionavam a relevância de uma vida de mãe, esposa e dona de casa, saíram para as ruas em protestos. (LUZ, 2012, p. 98)
\end{abstract}

Na década de 1980, o feminismo se expande para além da ideia de uma única condição feminina, caracterizando assim a $3^{a}$ onda. A partir desse período, desenvolve-se o conceito

2 Sufragistas nome dado a mulheres que participaram do movimento sufragista, que visava estender o direito ao voto às mulheres. 
gênero. Mas o que é gênero? De acordo com Joan Scott (1995, p. 21) é "uma categoria útil de análise histórica". A partir desse conceito, não se trata mais do sexo biológico de homens e mulheres que determinam os comportamentos, pois os indivíduos nascem com o sexo feminino ou masculino e a partir das interações sociais, midiáticas e políticas que se define o gênero, que está diretamente ligado à identidade ${ }^{3}$, ou seja, o gênero é diverso, já que as identidades são múltiplas e os grupos sociais diversos - etnias, classes, religiões etc.

Com o conceito de gênero, todo o discurso baseado no sexo biológico, que classifica mulheres inferiores a homens, desmonta-se, pois, as crianças são ensinadas a desempenhar papéis determinados pelas sociedades a partir de mecanismos sociais, dessa forma, mulheres não são inferiores e sim condicionadas a agir conforme a sociedade the impõe. A partir disso, também pode-se verificar que o gênero é ademais construído a partir da relação entre homens e mulheres (Luz, 2013). Por isso, é possivel afirmar que a $3^{\mathrm{a}}$ onda contribuiu muito para o fortalecimento das lutas por direitos para mulheres, uma vez que demonstra que além do sexo não existem diferenças físicas que limitam ou inferiorizam mulheres em relação aos homens.

Na década de 1970, as mulheres começaram a ter uma participação significativa no ensino superior. Neste artigo o objetivo é entender o motivo pelo qual a EaD é e pode ser tão importante para a educação das mulheres e para a sua contínua inserção no mercado de trabalho, por isso, a seguir será analisado o ensino por correspondência para moças até as mulheres no ensino à distância contemporâneo.

\section{Dos Cursos por Correspondências às Universidades}

A partir da análise dos anúncios de cursos por correspondência, foi possível refletir sobre quais cursos à distância eram ofertados para

3 Para entender o conceito de identidade ler HALL, Stuart. A identidade cultural da pós-modernidade. Rio de Janeiro: DP\&A. 2005. mulheres desde os chamados Anos Dourados até a explosão do movimento feminista na década de 1970. Com essa análise foi comprovada uma quantidade maior de mulheres no Ensino à Distância Contemporâneo.

As revistas femininas $O$ Cruzeiro e Capricho foram muito populares entre moças nas décadas de 40 e 60. A primeira era um periódico de variedades, que também tinha assuntos voltados ao público masculino, mas a maior parte da revista se destinava especialmente a mulheres e em suas páginas é possível encontrar desde conselhos amorosos até dicas de moda. Já a revista Capricho era um periódico de fotonovela, que exibia histórias de amor e paixão. Tanto uma quanto a outra, funcionavam como manuais de boas maneiras para mulheres, pois ditavam os comportamentos que deveriam ser seguidos e reforçavam ideias conservadoras de relações de gênero.

Os anúncios de ensino por correspondência dos periódicos selecionados são muito interessantes, pois refletem exatamente a mentalidade da época em relação aos cursos e profissões que mulheres deveriam seguir no período de 1958 a 1977. Quase todos os anúncios de cursos disponíveis nas revistas eram voltados ao ensino técnico e em grande parte voltados ao público masculino, mesmo que os assuntos das revistas fossem majoritariamente para mulheres. Na revista O Cruzeiro, de 15/02/1958, foi constatado que de cinco anúncios três eram exclusivamente para homens, pois utilizavam uma linguagem indicativa de masculino, além de fotos e depoimentos de homens. Esses três anúncios faziam propaganda de ensino técnico para a formação de contadores e relojoeiros, além de ofertarem cursos para a complementação de renda familiar, no qual os maridos e jovens poderiam aprender a montar e consertar rádios e televisores. Os outros dois anúncios são direcionados ao aprendizado da língua inglesa e não revelam se também abrangiam mulheres.

Anúncios de ensino por correspondência de 1958 que incluíam mulheres, geralmente, mostravam cursos que reforçavam a ideia de perpetuação de talentos e inclinações inatas de 
mulheres no mundo do trabalho, além de exibir depoimentos e imagens de mulheres em funções inferiores aos homens. Entre essas propagandas, destacavam-se as profissões de costureiras, cabeleireiras, maquiadoras, manicures e secretarias. Nesse período, as propagandas de cursos de madureza ${ }^{4}$ não continham imagens de mulheres e nunca as mencionavam em profissões consideradas masculinas, mas essa visão mudou gradativamente.

Mesmo que a mentalidade das décadas de 1950 e 1960 se manifestasse nas revistas e propagandas de ensino por correspondência da década de 1970, alguns anúncios já refletiam a ascensão de mulheres ao ensino, pois engrandeciam a Lei de Diretrizes e Bases de 1971 e demonstravam que mulheres também poderiam se tornar administradoras, advogadas, médicas, engenheiras e quaisquer outras profissões que quisessem. $O$ texto a seguir, do anúncio dos cursos da instituição Dom Bosco - Escolas Reunidas, ilustra bem o momento:

\author{
TRIUNFE! \\ Qualquer que seja a sua idade ou posi- \\ ção, faça-o!
}

Estudando por correspondência Ginásio, Clássico ou Científico

Agora sim! Estudando apenas cinco matérias: Português, Matemática, Geografia, História e Ciências, de acôrdo com a nova lei "Diretrizes e Bases da Educação", qualquer que seja a sua idade ou posição, você poderá obter o DIPLOMA do Ginásio, Clássico ou Científico, em apenas 10 mêses! Por intermédio do DOM BOSCO Escolas Reunidas, pioneira em todo o país dêsses maravilhosos cursos por correspondência, pelo mundialmente famoso método "PROFESSOR EM CASA", os jovens

4 Madureza era o nome do curso de educação de jovens e adultos, regulamento pela LDB de 1961, que ministrava disciplinas dos antigos ginásio e colegial. Posteriormente foi substituído pelo Projeto Minerva e mais tarde pelo Supletivo. Para mais informações acessar: www.educabrasil.com.br/madureza. e adultos de ambos os sexos terão abertas as portas das faculdades e poderão tornar-se Professôres, Advogados, Médicos, Engenheiros, Dentistas, Administradores de Empreza, etc. Nosso curso elaborado por professôres especializados é conhecido por milhares de pessoas em todo o Brasil às quais já abriu as portas do Sucesso! (1977, p. 77, n. 433)

Conforme o anúncio anterior, foi possível verificar que, de fato, o ensino por correspondência acompanhou as mudanças sociais e políticas ocorridas na década de 1970. Nas décadas seguintes, a entrada de mulheres no ensino superior se destacou cada vez mais em relação aos homens e no ensino a distância, de acordo com Censo EaD.Br de 2017/2018, organizado pela ABED. Verifica-se que as mulheres representam $55,7 \%$ dos alunos em graduações totalmente a distância e $66,9 \%$ dos discentes em cursos semipresenciais. Os cursos de maior predominância feminina são os da área de humanas, sobretudo, em Pedagogia. Atualmente, as mulheres são a maioria em todos os níveis de ensino e cada vez mais procuram por especializações, de acordo com dados recentes da Coordenação de Aperfeiçoamento de Pessoal de Nível Superior (CAPES).

No entanto, dois questionamentos podem ser feitos a partir da constatação da maioria feminina em relação a homens no ensino superior à distância. O primeiro é o por que as mulheres estão em maioria na EaD? E o segundo está relacionado a como o Ensino a Distância pode auxiliar nas lutas femininas pela conquista de igualdade salarial e social?

De acordo com Manuel Castells (2003, p. 167), vivemos em sociedades contemporâneas patriarcais, onde a autoridade do homem é imposta às mulheres e filhos pela legitimação da instituição familiar. Essa autoridade foi e é exercida de forma violenta e perpetuada desde a sua instituição. Segundo Castells (2003. p. 168) "a família patriarcal, base fundamental do patriarcalismo, tem vindo a ser contestada neste fim de milênio pelos processos, inseparáveis, de mudança do trabalho feminino e da 
consciencialização da mulher". Portanto, com as mudanças de mentalidades e novas configurações familiares, a mulher ganhou mais espaço no mundo do trabalho, pois teve mais acesso à educação. No entanto, a mulher passou a exercer trabalhos fora e dentro de casa, já que a sociedade patriarcal ainda é predominante e tem ideias conservadoras em relação às funções femininas, mesmo essa estrutura e pensamento sendo contestado.

Dessa forma a mulher passou a exercer duas funções, caracterizando assim a chamada dupla jornada de trabalho. Na dupla jornada de trabalho, as mulheres conciliam o emprego remunerado com os afazeres domésticos e para Luciane da Luz, a flexibilidade e baixo custo do EaD pode ser um dos motivos pelos quais as mulheres buscam e são a maioria na modalidade. De acordo com o Censo EaD.BR o perfil de alunos da EaD é composto principalmente pelas classes $C, D$ e $E$, e as mulheres que procuram essa modalidade estão em sua maioria nestes grupos sociais. Por isso, pode-se supor que a educação continuada de baixo custo, proporcionada pela modalidade, torna-se extremamente atrativa para mulheres que buscam melhores postos de trabalho, respondendo a primeira pergunta proposta anteriormente.

De acordo com Naila Kabeer (2015, p. 13), a educação pode ser uma importante ferramenta para o empoderamento feminino. Neste artigo adota-se o conceito de empoderamento da pesquisadora Kabber (2015, p.14) que o define como a habilidade de fazer escolhas adquirida por aqueles que não tinham poderes para decidir por si próprios. Nesse contexto, a educação é um meio pelo qual a mulher pode exercer o poder de escolher o que é melhor para a própria vida. No artigo "Gender equality and Women's empowerment: A critical analysis of the third millennium development goal"fica claro que mulheres de países subdesenvolvidos que tiveram acesso à educação, mesmo sendo básica, têm melhores condições de decidir pela segurança e saúde dos filhos, sofrem menos violência doméstica, têm mais consciência sobre a exploração que sofrem no mundo trabalho, podem ter mais participação nas decisões privadas e políticas e por isso, com o empoderamento, proporcionado principalmente pela educação, podem escolher contestar os papéis inferiorizados que exercem por conta da inequidade entre os gêneros.

Atualmente, o acesso feminino à educação é o sonho de ativistas como Malala Yousafzai ${ }^{5}$, que lutam para garantir esse direito a todas as meninas e mulheres ao redor do mundo, inclusive no Brasil. Mas como o Ensino a Distância pode auxiliar nas lutas femininas pela conquista de igualdade salarial e social? Supõe-se que mantendo suas características de democratização de ensino, com a iniciativa de universidades que garantam a qualidade dos cursos e que sejam abertas ao debate para garantir espaços virtuais inclusivos, com ações ainda mais inovadoras para alcançar pessoas ainda mais distantes, com cursos cujos planos de ensino visem a formação de cidadãos e profissionais de todos os gêneros em humanos capazes de agirem como respeitadores e cumpridores de direitos e deveres. A educação à distância, assim como o ensino presencial, tem a capacidade de empoderar mulheres de todos as classes sociais tornando-as mais conscientes e transformadoras de suas realidades, capacitando-as para que escolham melhores postos de trabalhos com as possibilidades de reivindicar boas condições e direitos iguais, livrando-as de violências, garantindo participação em espaços anteriormente exclusivamente masculinos como em cursos de exatas e em instituições sociais como a política.

\section{Considerações Finais}

Através deste estudo foi possível verificar que a EaD acompanhou as mudanças da sociedade em relação ao espaço feminino na educação e na sua inserção no mercado de trabalho, mas é indispensável refletir que mulheres, apesar de todo o avanço alcançado, ainda ocupam espaços inferiores, recebendo salários menores e desempenhando o papel de dona de casa. A partir dessa conjectura, a educação à distância torna-se uma importante

5 Para mais informações sobre o trabalho de educação feminina desenvolvido pela ativista Malala Yousafzai acessar o site www.malala.org. 
ferramenta para o empoderamento feminino, permitindo que a escolha seja um direito real.

Discussões em relação ao espaço feminino na educação e mercado de trabalho são cada vez mais relevantes para refletir as novas dinâmicas da sociedade da era da informação, estudada por Castells (2003). No entanto, ainda há pouca literatura sobre a questão de gênero relacionada à Educação à Distância, na qual mulheres são a maioria. Por isso, pesquisas e estudos nessa área são urgentes e extremamente importantes para dar voz a esse grupo social ainda submetido a ideologia patriarcal.

Existem possibilidades de aprofundar essa pesquisa na área de história da educação a partir de análises de materiais didáticos disponibilizados em cursos por correspondência dos anos 50 ou períodos anteriores, recomendados para mulheres a fim de investigar profundamente a mentalidade patriarcal enraizada que vem sendo superada. Também podem ser desenvolvidos estudos que analisem a interação de tutores e alunas e/ou outros grupos excluídos por meio de pesquisas e questionários nos quais os docentes e discentes possam expor suas facilidades e dificuldades ao escolher a educação a distância.

No contexto proposto, o presente artigo desempenha um importante papel ao discutir a importância do EaD na vida das mulheres a partir do estudo da história da educação à distância, da história da mulher na educação e sua inserção no mercado do trabalho aliados a conceituação da EaD e do gênero.

\section{Referências}

ASSOCIAÇÃO BRASILEIRA DE EDUCAÇÃO A DISTÂNCIA. Censo EaD. BR 2017 - Relatório analítico da aprendizagem a distância no Brasil. Curitiba: InterSaberes, 2018. Disponivel em:<http://www.abed.org.br/site/pt/midiateca/ censo_ead/>. Acesso em: 07 nov. 2018.

ACORDI, D. da R. Da chibata ao magistério: a trajetória da educação feminina no Brasil patriarcal. A Formação da Leitura no Brasil. São Paulo: Ática, 2001.
ARAÚJO JR., C. F.; SILVEIRA, I. F.; CECHINEL, C. A regulação da Educação Superior a Distância no Brasil: marcos de uma trajetória. Desafios da Educação a Distância: inovação e institucionalização. São Paulo: Terracota, 2016.

CASTELLS, M. O poder da identidade. [S.L.]: Editora Fundação Calouste Gulbenkian, 2003.

HALL, S. A identidade cultural da pós-modernidade. Rio de Janeiro: DP\&A. 2005.

INSTITUTO BRASILEIRO DE GEOGRAFIA E ESTATÍSTICA. Pesquisa Nacional por Amostra de Domicílios (PNAD). IBGE, 2017. Disponível em <www.ibge.gov.br>. Acesso em: 20 de out. 2018.

KABEER, N. Gender equality and women's empowerment: A critical analysis of the third millennium development goal 1. Gender \& Development. V. 13, 2010. Disponivel em: <http://www. tandfonline.com>. Acesso em: 07 nov. 2018.

LOURO, G. L. Mulheres na sala de aula. História das Mulheres no Brasil. São Paulo: Contexto, 2013.

LUZ, L. da. M. e EaD: Uma análise de gênero sobre o perfil dos(as) acadêmicos(as) na educação a distância no Brasil. Revista Maiêutica - Serviço Social. Indaial, v. 1, 2013.

MATOS, M. I., e BORELLI, A. Espaço feminino no mercado produtivo. Nova história das mulheres no Brasil. São Paulo: Contexto, 2012.

MATTAR, J. Guia de Educação a Distância. [s. l.]: Cengage Learning, 2011.

MENEZES, E. T. de; SANTOS, T. H. dos. Verbete Madureza. Dicionário Interativo da Educação Brasileira - Edicabrasil. São Paulo: Midiamix, 2001. Disponível em <http://www.educabrasil. com.br/madureza/>. Acesso em: 08 de jan. 2019. NISKIER, A. A Tecnologia da Esperança. Educação à Distância: A Tecnologia da Esperança. [s. l.]: Editora Loyola, 1999.

BASSANEZI PINSK, C. Mulheres dos Anos Dourados. São Paulo: Contexto, 2014.

Mulheres dos anos dourados. Editora Contexto, 2014. 
;PEDRO, J. M. Mulheres: Igualdade e Especificidade. História da Cidadania. São Paulo: Contexto, 2014.

REVISTA CAPRICHO. EDIÇÃO DE 1977. São Paulo: Editora Abril.

REVISTA O CRUZEIRO. Edições de 1958 a 1977. Rio de Janeiro: Diários Associados.

ROSEMBERG, F. Mulheres Educadas e a Educação de Mulheres. Nova história das mulheres no Brasil. São Paulo: Contexto, 2012.

SCOTT, J. Gênero: uma categoria útil para análise histórica. Educação \& Realidade. Porto Alegre, v. 20, n. 2, jul./dez. 1995. Disponível em: <http://www.obser-vem.com/upload/935db796164ce35091c80e10df659a66.pdf>. Acesso em: 20/11/2018.

VALENTE, J. A. Informática na educação no Brasil: Análise e Contextualização Histórica. $O$ computador na Sociedade do Conhecimento. Campinas: NIED, 1999. 